\title{
Research on Internet-Finance Risk Warning based on Big Data
}

\author{
Qipeng ZHANG ${ }^{1}$, Youtao $\mathrm{LUO}^{2}$, Shiguang FU ${ }^{1}$, Zhanpeng XU ${ }^{1}$, Yu XIAO ${ }^{1}$ \\ ${ }^{1}$ Zhejiang University of Technology, Hangzhou, China \\ ${ }^{2}$ Tsinghua University, Beijing, China
}

\begin{abstract}
Internet-Finance is expanding rapidly in the present era. However, the financial risk warning system has not been established. There is huge potential risk in the Internet-Finance. Based on the big data technology as the theoretical basis, this paper analyzes the types of potential risk of Internet Finance, and then points out the establishing principles of the system Internet-Finance risk warning. Finally, we give the risk early warning methods of Internet finance to guarantee the healthy and sustainable development of InternetFinance enterprises.
\end{abstract}

KEYWORD: big data; internet finance; risk warning

\section{CONCEPT OF BIG DATA}

Big data is a relatively abstract concept. Currently, the definition of the concept of big data is not uniform. Schonberg known as the "the first man who apply big data in business" points out that the "big" in big data does not refer to the absolute number but the processing mode. We will try to collect comprehensive data, complete data and synthetic data, at the same time, the use of mathematical methods to analyze and its modeling, mining behind the relationship, thus predicting the probability of event happening behind. The world famous management consulting company McKinsey's big data is defined as the data which cannot use traditional database software tools in a certain period of time, the contents of the acquisition management and processing of data set. The most representative definition of many big data definitions is the $3 \mathrm{~V}$ definition. The first $\mathrm{V}$ means volume, namely the data volume is huge; the second $\mathrm{V}$ means variety, namely there are a lot of data types in big data, such as text, images, audio, video and so on; The third V means volume velocity, that is the fast processing speed of big data. In addition, International Data Corporation (IDC) believes that big data should also have the high commercial value. IBM believes big data should be veracity. In short, the definition of big data concept can be based on $3 \mathrm{~V}$ or $4 \mathrm{~V}$ or $5 \mathrm{~V}$.

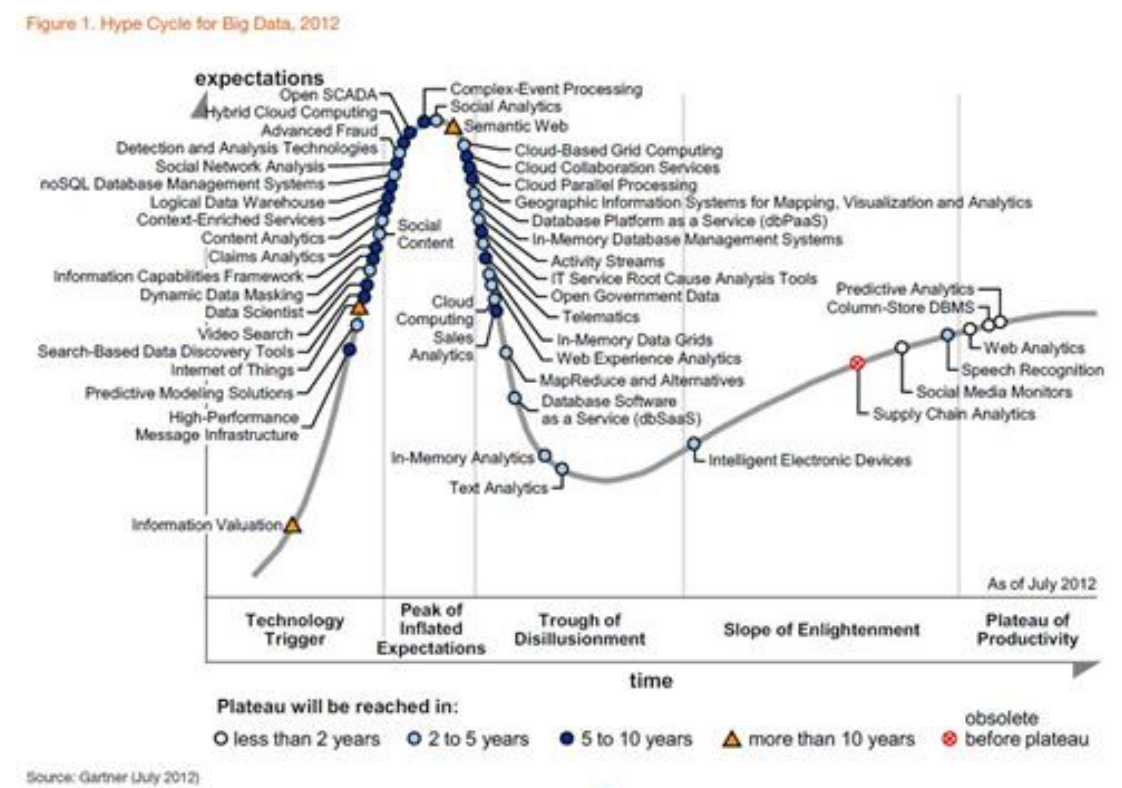

Figure 1. Hype circle of big data 


\section{CONCEPT AND RISKS OF INTERNET- FINANCE}

\subsection{Concept of Internet-Finance}

The Internet-Finance refers to a new financial implementation which relies on online payment, cloud computing, social networking, search engines and other Internet tools to realize payment and information intermediary business. Internet-Finance is not the simple combination of internet and finance, but a naturally occurring system after the receiving and acceptance of electronic commerce. It is a new mode and business based on mobile internet. It is also a combination of the financial industry and spirit of the internet.

\subsection{Risk of Industries Polymerization}

The financial industry and the Internet industry all belong to high risk industries. The risk of InternetFinance is much greater than traditional finance or the internet industry. Because of cross industry, nontraditional financial industry into the financial sector, the financial risk and control awareness of the existence of defects, such as limited capacity problem. Risk any Internet-Finance products is consistent with China's capital market, enterprises cannot ensure that investors can continuously obtain higher than the return on bank deposits. Once the reach the promised expected earnings or fund loss, brings the risk is great and. To avoid risks, some of the banks have been canceled the Internet-Finance products cooperation.

\subsection{Risk of Safe Payment}

As a financing payment platform, although it has been in the development of various kinds of safety protection measures, the Internet-Finance institutions also has the risk of safe payment. The reason is the mobile phone application software is open and easy to cause the mobile phone poisoning. Latent running in the mobile phone in the background after the personal information can be stolen easily. At the same time, mobile phone lost cause property damage examples have occurred, but also alert to all Internet consumers in mobile payment for mobile phone use knock. By some test found that the mobile phone is lost can easily lead to the Internet-Finance product property are many malicious take out, once triggered a heat to discuss have expressed concerns in the era of mobile interne. Mobile phone payment security is particularly worthy of attention.

\subsection{Risk of Safeguarding Rights}

At present, the Internet-Finance legal system is not perfect in our country. Consumer rights easily suffered an embarrassing situation. On the Internet the legality of government financial institutions without clearly defined; the relevant laws and regulations for online transactions in the provisions of the rights and obligations of the most is not clear; the lack of the management of the Internet consumer rights and interests protection should be relative and trial regulations; fuzzy understanding of the privacy of clients of the age of big data, privacy protection provisions lack; on the Internet-Finance illegal money laundering process and method does not have the thorough research, the money laundering regulations is not clear; in the network transactions, place of tort and damage result difficult to be precise definition in the investigation the police also have the corresponding the requirements and provisions of the amount of loss. It is difficult to seek public relief channels. We can only negotiate with operators.

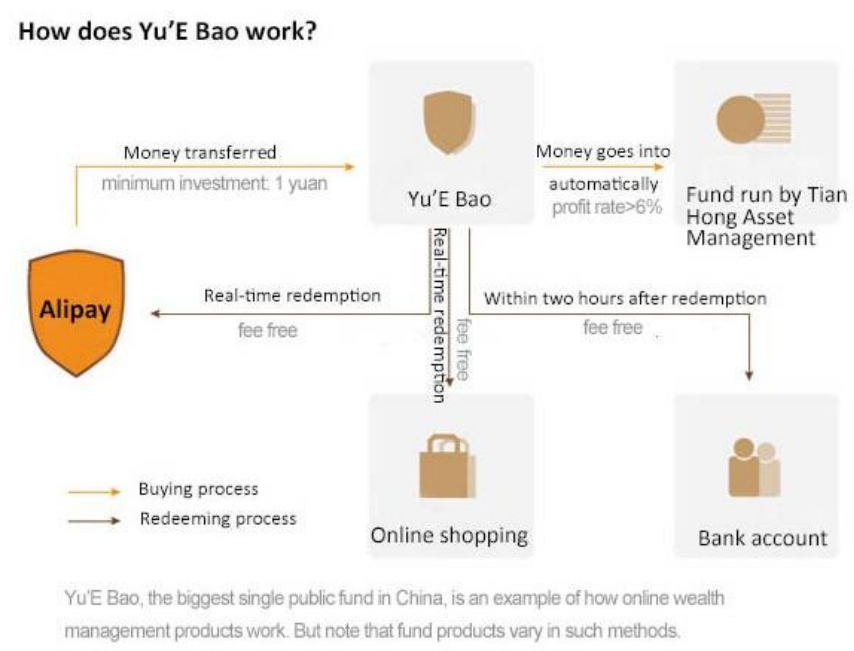

By He Yini / chinadaily.com.cn

Figure 2. The way Yu'E Bao works

\section{DESIGN PRINCIPLES OF EARLY WARNING SYSTEM BASED ON BIG DATA}

We design the early warning system of InternetFinance based on the systematic principle. The early warning system of financial risk is the Internet for Internet-Finance risk monitoring, forecasting, early warning system is a big system, the Internet must be covered the whole process of financial activities, consideration must be given to each participant to Internet-Finance activities, including financial services, financial products provider, intermediary agencies, users, and government regulators and so on, must consider all kinds of transactions, and even the public opinion trends. At the same time, also need to balance the country situation, macro economy, industry and other economic indicators.

We design the early warning system of InternetFinance based on the time-effectiveness principle. Because the Internet-Finance data has the characteristics of high speed, change and explained 
the importance of real-time processing is the purpose of real-time analysis of preventing and reducing financial risks, financial risks, timely recognition of judgments, timely carried on to the risk prediction and response, continuous in time, the contents should be consistent and comparable.

We design the early warning system of InternetFinance based on the operational principle. Operational principles in the collection, management of data, to identify and judge the benefit risk. In the system, the company is simple and reliable to combine with the actual situation; in the process of analyzing data, indicators, statistical methods and criteria to related analysis is easy operation. We not only can the fast recognition, judgment, forecast risk, make early warning, the source can distinguish risk.

We design the early warning system of InternetFinance based on the flexibility principle. The design principle of elasticity system should be compatible both financial risk early warning system, to ensure the normal operation of enterprises under the premise with the passage of time, to continue to improve and perfect to the system, ensure the system function module should be able to run independently and to avoid redundancy.

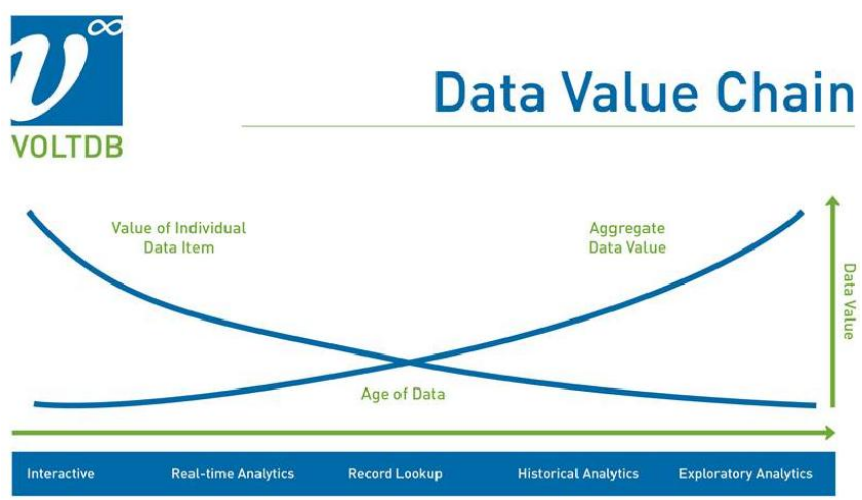

Figure 3. Data Valu Chain

\section{APPLICATION METHODS OF EARLY WARNING SYSTEM BASED ON BIG DATA}

The use of large data involves the Internet-Finance products is relatively small in domestic. The first reason is the domestic financial system is not perfect; the second reason is the data is always large but not fine. The difficulty of obtaining data exists and the problem of inaccurate, so to the large data of Internet finance brings a lot of problems, but also many attempts and especially in the aspect of risk control.

Without depending on central bank credit system under the condition of ecological system, risk control of domestic financial market spontaneously formed characteristic. The Internet-Finance enterprise risk control is broadly divided into two modes, one is control mode similar to Ali's wind, through their own system of large electric business transaction and payment information data to establish a closed system of credit rating and wind control model. Another is the numerous small and medium-sized Internet-Finance company by contributing data to the middle of a credit institution, and then to share credit information. Credit system is the central bank by commercial banks and other social institutions reporting data, combined with authentication center identity audit, provided to the bank credit and personal credit report query system. But for other credit institutions and interconnected financial firms currently does not provide direct inquiry service, at the same time a large number of individuals in this system there is no credit history, and these people are likely to have the corresponding credit record data system in other institutions, central bank credit system and foreign Internet-Finance company. Dynamic data collected from the small loan company net credit company and some of the line, as the Internet-Finance enterprises to provide a credit inquiry, poor user information query, query and other diversified credit rating service is currently on the market the company is promoting the work of credit. With more and more enterprises to join the rules of the game, the outline is composed of a large number of dynamic data of credit profiles will also be more and more clear.

In addition, the Internet-Finance cannot operate normally without the national laws, regulations, policy support, supervision, participants and investors. The supervision department should perfect the laws, regulations and relevant policies as soon as possible to create a fair competition environment and protect Internet-Finance participant's property safety. We should speed up the introduction of relevant policies, make the Internet-Finance business scope clear and establish the effective access and exit mechanism. Enterprise should public disclosure of relevant data and give full play to the InternetFinance investors, participants to avoid financial risks.

\section{REFERENCES}

[1] Ji Qiang, Guo Jianfeng(2014) Energy Finance in the Age of Big Data, Bulletin of the Chinese Academy of Sciencest.

[2] Changjun Jiang, Zhijun Ding, Junli Wang, Chungang Yan. (2014) Big Data Resource Service Platform for the InternetFinance Industry. Chinese Science Bulletin.

[3] Ronald Rousseau. (2012) A View on Big Data and Its Relation to Informetrics. Chinese Journal of Library and Information Science

[4] Fan Wenfei, Huai Jinpeng. Querying (2014) Big Data: Bridging Theory and Practice. Journal of Computer Science \& Technology. 